\title{
The protective effects of preconditioning decline in aged patients undergoing coronary artery bypass grafting
}

\author{
Zhong-Kai Wu, MD \\ Erkki Pehkonen, MDa \\ Jari Laurikka, MDa \\ Liisa Kaukinen, $M D^{b}$ \\ Eva L. Honkonen, MD \\ Seppo Kaukinen, $M D^{b}$ \\ Pekka Laippala, $\mathrm{PhD}^{\mathrm{c}, \mathrm{d}}$ \\ Matti R. Tarkka, MDa
}

From the Division of Cardiothoracic Surgery, ${ }^{\mathrm{a}}$ Department of Anesthesiology and Intensive Care, ${ }^{\mathrm{b}}$ Tampere University Hospital, Research Unit of Tampere University Hospital, ${ }^{\mathrm{c}}$ and the School of Public Health, Biometry Unit, University of Tampere, ${ }^{\mathrm{d}}$ Tampere, Finland.

Supported by the Research Foundation of Tampere University Hospital.

Received for publication Dec 20, 2000; revisions requested April 13, 2001; revisions received May 1, 2001; accepted for publication May 15, 2001.

Address for reprints: Matti Tarkka, MD, Department of Surgery, Division of Cardiothoracic Surgery, Tampere University Hospital, 33521 Tampere, Finland (E-mail: matti.tarkka@tays.fi).

J Thorac Cardiovasc Surg 2001;122:972-8

Copyright () 2001 by The American Association for Thoracic Surgery

$0022-5223 / 2001 \$ 35.00+0 \quad \mathbf{1 2 / 1 / 1 1 7 2 7 9}$

doi:10.1067/mtc.2001.117279
Objective: We sought to investigate the effects of myocardial ischemic preconditioning in adult and aged patients undergoing coronary artery bypass grafting.

Methods: Eighty patients with 3-vessel disease undergoing coronary artery bypass grafting were randomized into one of the following groups: adult ischemic preconditioning, adult control, aged ischemic preconditioning, and aged control. Hemodynamic data and cardiac troponin I values were compared between the groups. The ischemic preconditioning groups received 2 periods of 2 minutes of ischemia, followed by 3 minutes of reperfusion. The Student $t$ test, $\chi^{2}$ test, and analysis of variance for repeated measures were used for the statistical analysis.

Results: The baseline for right ventricular ejection fraction and cardiac index was similar. Right ventricular ejection fraction was depressed after the operation in all groups. Ischemic preconditioning significantly improved the recovery of right ventricular ejection fraction and cardiac index after the operation in adult patients $(P=$ .013 and .001 , respectively), but in the aged group there was no difference in the changes of ejection fraction and cardiac index $(P=.232$ and .889 , respectively). The cardiac troponin I value in the adult patients subjected to ischemic preconditioning was lower than that in the adult control subjects $(P=.046)$, but in aged patients undergoing ischemic preconditioning, the value was similar to that in aged control subjects $(P=.897)$. Ischemic preconditioning also resulted in a shorter postoperative mechanical ventilation time and in less inotropic use in the adult group.

Conclusion: Ischemic preconditioning protects the heart from ischemic reperfusion injury in adult patients undergoing coronary artery bypass grafting. The beneficial effects of ischemic preconditioning are manifested as a better recovery of right ventricular and global hemodynamic function, cellular viability, and surgical outcome. The protective effect of ischemic preconditioning is diminished in aged patients undergoing coronary bypass.

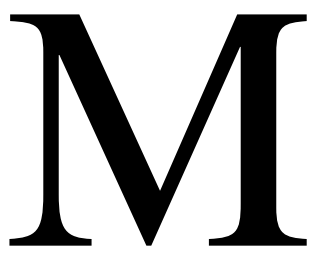

yocardial ischemic preconditioning (IP) has been extensively studied in various kinds of experimental models, as well as in human subjects. It has proved a potent endogenous factor in preserving high-energy phosphates, suppressing arrhythmias, delaying myocardial infarction, and improving postischemic functional recovery. ${ }^{1,2}$ Different experimental models and conditions simulating cardiac surgery have also been investigated. ${ }^{2,3}$

Published reports on the IP protective effects in the aged heart are controversial. Animal model studies show that the effect is lost in the senescent ${ }^{4}$ or even middle- 
TABLE 1. Reports of IP in cardiac surgery

\begin{tabular}{|c|c|c|c|}
\hline Authors & Age of patients (y) & IP protocol & Results \\
\hline $\begin{array}{l}\text { Yellon and coworkers }{ }^{12} \text { and } \\
\text { Alkhulaifi and coworkers }\end{array}$ & $58.0 \pm 2.8$ & 2 cycles, $3 \min \mathrm{l} / 2 \min \mathrm{R}$ & Preserved high-energy phosphate \\
\hline Lu and coworkers ${ }^{14}$ & $31.9 \pm 3.6$ & 2 cycles, $2 \min \mathrm{I} / 3 \min \mathrm{R}$ & $\begin{array}{l}\text { Preserved high-energy phosphate, improved heart } \\
\text { performance }\end{array}$ \\
\hline Illes and Swoyer ${ }^{15}$ & $61.6 \pm 1.5$ & 1 cycle, $1 \mathrm{~min} \mathrm{l} / 5 \mathrm{~min} \mathrm{R}$ & $\begin{array}{l}\text { Improved heart performance, decreased need } \\
\text { for inotropic support }\end{array}$ \\
\hline Li and cowrokers ${ }^{16}$ & $32 \pm 4$ & 2 cycles, $3 \min \mathrm{l} / 2 \min \mathrm{R}$ & $\begin{array}{l}\text { Lower release of CK-MB and better } \\
\text { hemodynamic outcome, increased myocardial } \\
\text { superoxide dismutase and decreased } \\
\text { malondialdehyde activity }\end{array}$ \\
\hline Szemagala and coworkers ${ }^{17}$ & $56.4 \pm 9.2$ & 1 cycle, 4 min $\mathrm{l} / 6 \min \mathrm{R}$ & Decreased CTnT release \\
\hline Jenkins and coworkers ${ }^{18}$ & $57 \pm 2$ & 2 cycles, $2 \min \mathrm{l} / 3 \min \mathrm{R}$ & Decreased CTnT release \\
\hline Perrault and coworkers ${ }^{19}$ & $68 \pm 3$ & 1 cycle, $3 \min \mathrm{I} / 2 \min \mathrm{R}$ & $\begin{array}{l}\text { CK-MB and lactate increased, no clinical } \\
\text { adverse and protective effects }\end{array}$ \\
\hline Kaukoranta and coworkers ${ }^{20}$ & $63.9 \pm 2.1$ & 1 cycle, $5 \mathrm{~min} \mathrm{l} / 5 \mathrm{~min} \mathrm{R}$ & No better effect of IP \\
\hline Cremer and coworkers ${ }^{21}$ & $62.1 \pm 4.6$ & 2 cycles, $5 \mathrm{~min} \mathrm{I} / 10 \mathrm{~min} \mathrm{R}$ & Increased inotropic use \\
\hline
\end{tabular}

$I$, Ischemia; $R$, reperfusion; $C K-M B$, creatine kinase MB.

aged rat heart, ${ }^{5}$ whereas in senescent sheep (5.7-8.0 years) the response is well conserved. ${ }^{6}$ Abete and colleagues ${ }^{7}$ found that the angina-induced IP protection against myocardial infarction was lost in aged patients. Warm-up phenomenon, a counterpart of IP, can be observed in adult, but not in older, patients. ${ }^{8}$ A recent report shows that exerciseinduced IP protects the following ischemia, but it only occurs in adult, and not in elderly, patients; this reinforces the hypothesis of an age-related reduction of IP in the aged heart. ${ }^{9}$ However, Kloner and colleagues ${ }^{10}$ have shown that the protective effect of preinfarct angina to the subsequent myocardial infarction persists also in patients aged 60 years or older.

More recently, articles report the application of IP in cardiopulmonary bypass (CPB) surgery. The outcome, however, has been controversial. Differences in study protocols and patients might be the reason for the discrepancies (Table 1). ${ }^{11-21}$ No investigation of the age-related aspects of the IP phenomenon has been made in human cardiac surgery to our knowledge. The aim of the present study was to investigate the myocardial performance after IP in differently aged patients undergoing coronary artery bypass grafting (CABG).

\section{Materials and Methods}

The study design was accepted by the Ethical Committee of Tampere University Hospital, Finland, and informed consent was obtained from all patients.

\section{Patients}

Eighty patients with 3-vessel coronary artery disease undergoing CABG were randomized into an IP group $(n=40)$ and a control group $(n=40)$. According to the median age (68 years), patients were further divided into an adult IP group and an adult control group $(<68$ years) and an aged IP group and an aged control ( $\geq 68$ years). Patients with low ejection fractions $(<35 \%)$, recent myocardial infarction $(<3$ months), additional cardiac diseases, severe noncardiac diseases, and calcified or severely dilated ascending aortas were excluded.

The preoperative data of the patients were similar between the IP and the control groups. There were no statistically significant differences in age, sex, New York Heart Association class, left ventricular ejection fraction, vessel diseases, previous myocardial infarction, left ventricular hypertrophy, diabetes, or preoperative medication use between the 2 groups. The numbers of vessels bypassed, crossclamping time, and CPB time were also similar (Table 2).

\section{Preconditioning Protocol}

After establishing CPB and running the pump to empty the heart, the ascending aorta was occluded by means of crossclamping for 2 minutes, followed by 3 minutes of reperfusion; the procedure was repeated once. In the control group the pump was also run for 10 minutes before routine operation. Normothermia was maintained during the procedure.

\section{Anesthesia, CPB, and Surgical Technique}

A standardized anesthetic technique was used with sufentanil, midazolam, and pancuronium bromide. CPB with nonpulsatile perfusion flow $\left(2.2-2.4 \mathrm{~L} \cdot \mathrm{min}^{-1} \cdot \mathrm{m}^{-2}\right)$ was conducted by using membrane oxygenators with arterial line filtration. Mild hypothermia $\left(32^{\circ} \mathrm{C}\right)$ was maintained without topical cooling. Blood from the pump reservoir was mixed with crystalloid in a ratio of $4: 1$, yielding a cardioplegia solution with a 0.21 hematocrit value and a $21 \mathrm{mmol} / \mathrm{L}$ potassium concentration in the initial dose and 9 $\mathrm{mmol} / \mathrm{L}$ in subsequent doses. In antegrade delivery cardioplegia was administered at a pressure of $80 \mathrm{~mm} \mathrm{Hg}$, and in retrograde delivery it was administered at a pressure of 30 to $40 \mathrm{~mm} \mathrm{Hg}$, with a flow of at least $200 \mathrm{~mL} / \mathrm{min}$. The initial high-potassium cardioplegia was given for 1.5 minutes in an antegrade fashion and then for 2.5 minutes in a retrograde fashion at a temperature of $6^{\circ} \mathrm{C}$ to $9^{\circ} \mathrm{C}$. Reinfusion of cardioplegia was administered for 1 minute 


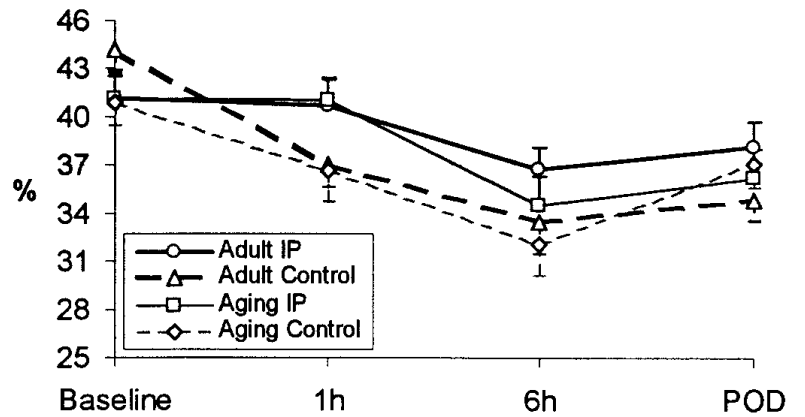

Figure 1. RVEF in adult and aged patients undergoing CABG after operation. Data are presented as means \pm SEM.

with retrograde delivery and to vein grafts after completion of each distal vein graft anastomosis. Warm cardioplegia $\left(37^{\circ} \mathrm{C}\right)$ was given in a retrograde fashion for 3 minutes before crossclamp release. Surgical techniques were the same in all cases. Aortic root and 2stage single venous cannulas were used for CPB. Distal anastomoses were made in the order of right coronary artery-circumflex artery-left anterior descending artery. The proximal anastomoses were constructed in a reverse order and during aortic crossclamping. The left anterior descending artery was grafted with the left internal thoracic artery in all patients.

\section{Hemodynamic Measurements and Treatment}

Hemodynamic data were collected at 4 time points: (1) baseline (before induction of anesthesia); (2) 1 hour after declamping; (3) 6 hours after declamping; and (4) on the first postoperative day (POD). Heart rate (HR), mean arterial pressure (MAP), central venous pressure (CVP), mean pulmonary artery pressure (MPAP), pulmonary capillary wedge pressure (PCWP), cardiac output (CO), and right ventricular ejection fraction (RVEF) were monitored. Derived cardiovascular variables, including cardiac index (CI) and right ventricular end-diastolic volume index (RVEDVI), were calculated with standard formulas. All measurements based on the thermodilution technique were made at end expiration in triplicate with ice-cold saline solution. The mean value of 3 consecutive measurements at each time point was registered.

Perioperatively, volume infusion was designed to maintain filling pressures at least at the preoperative level and optimal for heart performance. Inotropes (dopexamine or adrenaline) were used to maintain the CI above $2.0 \mathrm{~L} \cdot \mathrm{min}^{-1} \cdot \mathrm{m}^{-2}$. Amrinone with noradrenaline was used when dopexamine or adrenaline proved insufficient to maintain the CO. They were applied after release of crossclamping and continued for at least 6 hours. Inotropes were not discontinued at the time points when hemodynamic data were measured.

\section{Cardiac Troponin I}

Blood samples were collected from peripheral vessels (1) before CPB as baseline, (2) 5 minutes after declamping, (3) 6 hours after declamping, (4) at the first POD, and (5) at the second POD. Samples were collected in heparin-coated plastic tubes and centrifuged. Serum samples were measured with a Chiron ACS180 analyzer (Chiron Diagnostics Corp, East Walpole, Mass) by using a direct chemiluminescence method.

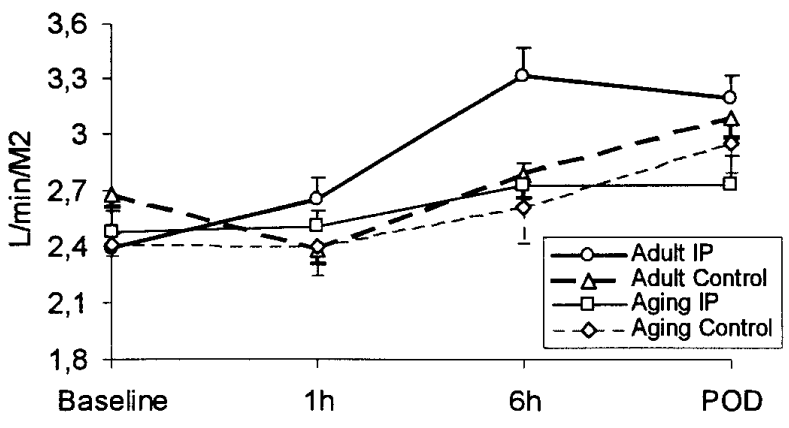

Figure 2. $\mathrm{Cl}$ in adult and aged patients undergoing CABG after operation. Data are presented as means \pm SEM.

\section{Statistics}

The 2-sample Student $t$ test (2-tailed) was used for continuous data. The $\chi^{2}$ or Fisher exact tests were used for categoric data when comparing variables between the IP and control groups in the adult or aged patients. Analysis of variance (ANOVA) for repeated measures was used to test repeated observation variables after the operation. Data are presented as means \pm SD. Statistical analyses were made with an SPSS/Windows (version 9.0) statistical package program.

\section{Results}

\section{Hemodynamics in Adult Patients}

The hemodynamic variables, namely HR, MAP, CVP, MPAP, PCWP, and RVEDVI, were similar between the IP and control groups (Table 3). There was no difference between the IP and control groups in the baseline level of $\operatorname{RVEF}(41.2 \% \pm 6.2 \%$ vs $44.2 \% \pm 7.0 \%, P=.167, t$ test $)$. The baseline level of CI in the control group had a slight tendency to be higher than that in the IP patients $(2.39 \pm 0.37$ vs 2.68 $\pm 0.52 \mathrm{~L} \cdot \mathrm{min}^{-1} \cdot \mathrm{m}^{-2}$ in the IP and control groups, respectively; $P=.058, t$ test). RVEF was depressed after the operation in both groups, with the depression being milder in the IP group ( $P=.013$, ANOVA for repeated measures; Figure 1). IP resulted in better recovery of $\mathrm{CI}$ after the operation $(P$ $=.001$, ANOVA for repeated measures; Figure 2).

\section{Hemodynamics in Aged Patients}

The hemodynamic variables, namely HR, MAP, CVP, MPAP, PCWP, and RVEDVI, were similar between the IP and control groups (Table 3). The baseline levels of RVEF and CI were similar between the IP and the control groups $(41.2 \% \pm 6.0 \%$ vs $41.0 \% \pm 6.3 \%, P=.895$ and $2.47 \pm 0.31$ vs $2.41 \pm 0.28 \mathrm{~L} \cdot \mathrm{min}^{-1} \cdot \mathrm{m}^{-2}, P=.519$, respectively, $t$ test). In the IP group there was a slight tendency toward better recovery in RVEF immediately after the operation, but it was not statistically significant $(P=.126$, ANOVA for repeated measures; Figure 1). IP did not induce better recovery of $\mathrm{CI}$ after the operation $(P=.889$, ANOVA for repeated measures; Figure 2). 
TABLE 2. Preoperative data and perioperative course

\begin{tabular}{|c|c|c|c|c|}
\hline & $\begin{array}{l}\text { Adult IP patients } \\
\qquad(\mathbf{n}=\mathbf{2 1})\end{array}$ & $\begin{array}{l}\text { Adult control subjects } \\
\qquad(\mathbf{n}=18)\end{array}$ & $\begin{array}{l}\text { Aged IP patients } \\
\qquad(n=19)\end{array}$ & $\begin{array}{l}\text { Aged control subjects } \\
\qquad(\mathrm{n}=22)\end{array}$ \\
\hline Age (y) & $57.0 \pm 8.0$ & $58.9 \pm 6.5$ & $71.8 \pm 2.7$ & $73.2 \pm 3.3$ \\
\hline $\operatorname{Sex}(F / M)$ & $3 / 18$ & $2 / 16$ & $6 / 13$ & $8 / 14$ \\
\hline NYHA class (II, III, or IV) & $3.3 \pm 0.7$ & $3.6 \pm 0.6$ & $3.5 \pm 0.5$ & $3.4 \pm 0.6$ \\
\hline $\operatorname{LVEF}(\%)$ & $60.7 \pm 12.4$ & $63.5 \pm 8.8$ & $59.4 \pm 10.2$ & $62.6 \pm 11.5$ \\
\hline LAD (stenosis \%) & $80.0 \pm 24.0$ & $82.3 \pm 15.4$ & $81.0 \pm 16.0$ & $78.7 \pm 23.1$ \\
\hline LCX (stenosis \%) & $78.5 \pm 23.8$ & $76.5 \pm 15.6$ & $81.6 \pm 22.8$ & $74.0 \pm 7.6$ \\
\hline RCA (stenosis \%) & $84.0 \pm 24.8$ & $83.5 \pm 17.4$ & $85.0 \pm 16.7$ & $76.0 \pm 25.7$ \\
\hline $\mathrm{LM}>50 \%(\mathrm{n})$ & 8 & 7 & 8 & 7 \\
\hline MI history (n) & 13 & 8 & 7 & 9 \\
\hline LV hypertrophy (n) & 5 & 3 & 3 & 4 \\
\hline Diabetes (n) & 5 & 7 & 4 & 4 \\
\hline ACE inhibitor (n) & 6 & 5 & 3 & 3 \\
\hline $\mathrm{Ca}^{++}$antagonist (n) & 4 & 6 & 8 & 6 \\
\hline Vessels bypassed (n) & $3.9 \pm 0.8$ & $3.6 \pm 1.0$ & $3.8 \pm 0.8$ & $3.6 \pm 0.8$ \\
\hline Crossclamping (min) & $84.0 \pm 20.7$ & $77.4 \pm 19.3$ & $78.7 \pm 14.6$ & $76.4 \pm 13.1$ \\
\hline CPB time (min) & $119.0 \pm 20.8$ & $112.5 \pm 22.1$ & $110.1 \pm 18.9$ & $106.5 \pm 18.3$ \\
\hline
\end{tabular}

Similar preoperative data and operative courses were found between the IP and control groups both in the adult and aged patients. Data are presented as means $\pm S D$. NYHA, New York Heart Association; $L V E F$, left ventricular ejection fraction; $L A D$, left anterior ascending artery; $L C X$, left circumflex artery; $R C A$, right coronary artery; $L M$, left main coronary artery; $M I$, myocardial infarction; $L V$, left ventricular; $A C E$, angiotensin-converting enzyme.

\section{Cardiac Troponin I}

The baselines of serum cardiac troponin I (CTnI) in the groups were similar $(0.19 \pm 0.04$ vs $0.19 \pm 0.08 \mu \mathrm{g} / \mathrm{L}$ in the adult IP and control groups, $P=.966$, and $0.23 \pm 0.08$ vs $0.15 \pm 0.03 \mu \mathrm{g} / \mathrm{L}$ in the aged IP and control groups, $P=$ .360 , respectively, $t$ test). There was a massive release of CTnI after the operation, and this did not recover until the second POD. The CTnI values in adult patients undergoing IP were lower than those in adult control subjects $(P=.046$, ANOVA for repeated measures), whereas there was no statistically significant difference in the CTnI values between aged patients undergoing IP and control patients $(P=.897$, ANOVA for repeated measures; Figure 3).

\section{Surgical Outcome}

The period of mechanical ventilation was significantly shorter in adult patients undergoing IP than in adult control subjects $(P=.030, t$ test). There was no statistical significance in the period of mechanical ventilation between the aged IP and the aged control subjects $(P=.187, t$ test). The length of stay in the intensive care unit was similar between the groups. More patients in the adult group undergoing IP were free of inotropes $(P=.043$, Fisher exact test $)$, and the period of inotropic medication was also shorter than that in adult control subjects $(P=.031, t$ test). The difference in inotropic support in the aged patients was similar in those undergoing IP and the control subjects (Table 4). There was no perioperative myocardial infarction. No intra-aortic balloon pump was used.
CTnl

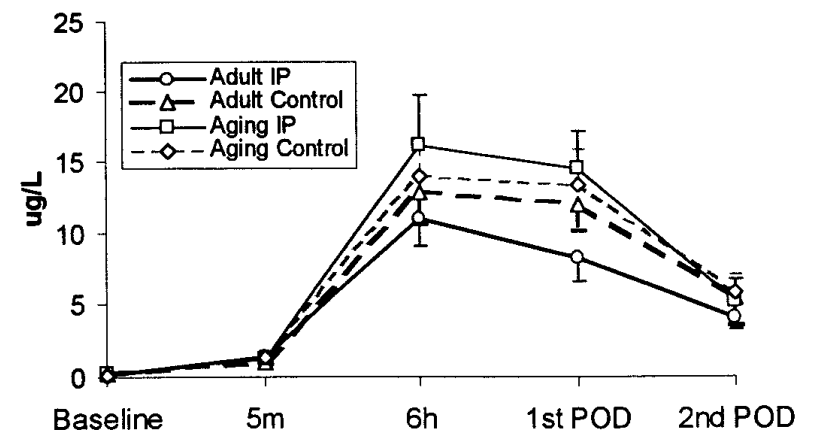

Figure 3. CTnl in adult and aged patients undergoing CABG after operation. Data are presented as means \pm SEM.

\section{Discussion}

Myocardial IP has been extensively studied in various kinds of experimental models, as well as in human subjects. ${ }^{1-3}$ However, reports on the IP effects in cardiac surgery are few in number. There are several studies showing that IP is effective in preserving high-energy phosphate, ${ }^{12-14}$ improving heart performance, ${ }^{14-16}$ reducing CTnI release, ${ }^{17,18}$ and increasing myocardial superoxide dismutase and decreasing malondialdehyde activity ${ }^{16}$ during cardiac surgery. There are also controversial reports as to the safety and effectiveness of IP during CPB surgery. ${ }^{19-21}$ Difference in the IP protocol and study subjects might be the reason for discrepancy. Age- 
TABLE 3. Hemodynamic data

\begin{tabular}{|c|c|c|c|c|c|}
\hline & Group & Baseline & $1 \mathrm{~h}$ declamping & $6 \mathrm{~h}$ declamping & First POD \\
\hline \multirow[t]{4}{*}{ HR (beats/min) } & Adult IP & $56.0 \pm 11.7$ & $78.5 \pm 14.6$ & $86.7 \pm 14.4$ & $80.1 \pm 10.6$ \\
\hline & Adult control & $60.9 \pm 10.1$ & $77.8 \pm 17.8$ & $87.0 \pm 27.1$ & $84.4 \pm 10.3$ \\
\hline & Aged IP & $55.7 \pm 6.9$ & $78.3 \pm 17.0$ & $87.5 \pm 13.6$ & $75.2 \pm 8.9$ \\
\hline & Aged control & $59.1 \pm 10.7$ & $76.7 \pm 13.8$ & $86.2 \pm 14.5$ & $80.2 \pm 12.6$ \\
\hline \multirow[t]{4}{*}{$\mathrm{MAP}(\mathrm{mm} \mathrm{Hg})$} & Adult IP & $87.1 \pm 14.5$ & $76.8 \pm 9.7$ & $80.2 \pm 12.8$ & $77.9 \pm 11.7$ \\
\hline & Adult control & $94.0 \pm 13.5$ & $78.9 \pm 6.7$ & $76.1 \pm 11.3$ & $80.4 \pm 11.8$ \\
\hline & Aged IP & $88.0 \pm 12.3$ & $75.1 \pm 9.1$ & $75.9 \pm 12.4$ & $74.6 \pm 9.1$ \\
\hline & Aged control & $89.4 \pm 14.3$ & $75.7 \pm 14.3$ & $79.4 \pm 11.2$ & $77.2 \pm 11.0$ \\
\hline \multirow[t]{4}{*}{ CVP $(\mathrm{mm} \mathrm{Hg})$} & Adult IP & $6.6 \pm 2.6$ & $9.2 \pm 1.9$ & $10.0 \pm 2.7$ & $8.8 \pm 2.3$ \\
\hline & Adult control & $8.1 \pm 2.2$ & $9.4 \pm 2.9$ & $10.3 \pm 2.8$ & $8.6 \pm 3.4$ \\
\hline & Aged IP & $8.1 \pm 2.7$ & $10.2 \pm 2.0$ & $10.3 \pm 2.7$ & $9.1 \pm 3.6$ \\
\hline & Aged control & $7.8 \pm 2.9$ & $9.9 \pm 2.4$ & $11.1 \pm 3.3$ & $7.9 \pm 2.5$ \\
\hline \multirow[t]{4}{*}{ MPAP (mm Hg) } & Adult IP & $19.0 \pm 7.2$ & $19.7 \pm 8.2$ & $23.1 \pm 4.9$ & $21.2 \pm 3.8$ \\
\hline & Adult control & $20.3 \pm 5.4$ & $20.0 \pm 6.0$ & $23.6 \pm 5.8$ & $20.6 \pm 5.5$ \\
\hline & Aged IP & $20.3 \pm 4.9$ & $19.3 \pm 3.6$ & $23.1 \pm 5.7$ & $20.9 \pm 3.9$ \\
\hline & Aged control & $20.6 \pm 9.5$ & $20.8 \pm 4.4$ & $23.6 \pm 5.2$ & $20.5 \pm 4.7$ \\
\hline \multirow[t]{4}{*}{ PCWP (mm Hg) } & Adult IP & $12.1 \pm 3.9$ & $10.4 \pm 6.7$ & $11.1 \pm 3.1$ & $11.0 \pm 2.3$ \\
\hline & Adult control & $13.1 \pm 3.5$ & $11.6 \pm 3.2$ & $11.2 \pm 3.4$ & $10.7 \pm 2.9$ \\
\hline & Aged IP & $11.4 \pm 3.2$ & $11.3 \pm 2.2$ & $10.5 \pm 3.5$ & $11.7 \pm 2.2$ \\
\hline & Aged control & $12.7 \pm 5.9$ & $11.2 \pm 2.8$ & $11.4 \pm 3.2$ & $11.0 \pm 2.3$ \\
\hline \multirow[t]{4}{*}{ RVEDVI $\left(\mathrm{mL} / \mathrm{m}^{2}\right)$} & Adult IP & $103.3 \pm 14.8$ & $86.9 \pm 20.5$ & $92.5 \pm 15.6$ & $98.9 \pm 19.3$ \\
\hline & Adult control & $101.1 \pm 21.8$ & $82.3 \pm 24.2$ & $90.2 \pm 24.5$ & $105.5 \pm 29.3$ \\
\hline & Aged IP & $106.1 \pm 24.2$ & $77.7 \pm 11.1$ & $92.1 \pm 23.0$ & $96.6 \pm 18.0$ \\
\hline & Aged control & $100.6 \pm 12.9$ & $85.9 \pm 20.6$ & $93.9 \pm 27.6$ & $98.0 \pm 19.9$ \\
\hline
\end{tabular}

There were no statistically significant differences between the IP and control groups in the adult or in the aged patients. Data are presented as means \pm SD.

TABLE 4. Postoperative care

\begin{tabular}{lcccc}
\hline & Adult IP & Adult control & Aged IP & Aged control \\
\hline Mechanical ventilation (h) & $11.3 \pm 3.5$ & $16.3 \pm 9.4^{*}$ & $13.4 \pm 3.0$ & $20.1 \pm 22.4$ \\
Stay in ICU (h) & $28.2 \pm 17.2$ & $37.4 \pm 22.5$ & $40.8 \pm 31.5$ & $46.2 \pm 41.0$ \\
Free of inotropes (n) & 11 & $3^{*}$ & 4 & 5 \\
Duration of inotropes (h) & $6.7 \pm 10.2$ & $13.9 \pm 9.6^{*}$ & $13.7 \pm 9.6$ & 10 \\
Dopexamine or adrenaline (n) & 5 & $10^{*}$ & 11 & 15 \\
Amrinone-noradrenaline (n) & 9 & 10 & 10 \\
\hline
\end{tabular}

Data are presented as means \pm SD. ICU, Intensive care unit.

${ }^{*} P<.05$, difference between IP and control group in the same age groups.

related factors may also play an important role..$^{4,5,7-9}$ As far as we know, the possible relation of the controversial result of IP in cardiac surgery has not been studied.

Our present findings suggested that preconditioning with 2 periods of 2-minute ischemia, followed by 3 minutes of reperfusion, was cardioprotective during CABG operations with cold-blood cardioplegia in adult patients. These beneficial effects of IP included better recovery of right ventricular function, improved global hemodynamic performance after the operation, and preserved cellular viability.

There are controversial reports as to whether IP is a phenomenon confined to the young myocardium. ${ }^{4-10}$ Our results suggested that the improved hemodynamic outcome and cellular viability were indeed closely associated with the age of the patients undergoing IP. It was clearly demonstrated that the protective IP effects were not present in aged patients undergoing CABG, which is in accord with previous observations of loss of IP in the aged heart., ${ }^{4,5,7-9}$

The precise mechanism of IP remains unknown. Brief episodes of myocardial ischemia result in the production of adenosine, norepinephrine, free radicals, and bradykinin. These chemical factors act on one or more types of myocyte receptor (eg, adenosine $A_{1}$, muscarinic receptor, and $\alpha$ sympathetic receptor) and result in translocation and activation of tyrosine kinase and protein kinase $\mathrm{C}$ to the cellular membrane, working with inhibitory G-protein to subsequently 
phosphorate the adenosine triphosphate-dependent potassium channel to trigger IP response. Increased release of one agonist or stimulation by more cycles of brief ischemic stimuli can compensate for the lack of another to achieve the protective effect. Protein kinase $\mathrm{C}$ translocates from cytosol to the cell membrane after activation and mediates phosphorylation of target proteins, ion channels, and myofilaments to achieve the effect. The delayed cardiac adaptation is consistent with induced gene transcription and the subsequent translocation of protective molecular proteins, including proto-oncogenes, stress proteins, and antioxidant enzyme systems. ${ }^{2,22}$

The aged myocardium evinces decreased adrenergic responsiveness, altered coronary microcirculation, impaired calcium transport, and impaired excitation-contraction coupling. Its maximal oxygen uptake decreases, and the rate of this decline accelerates with age. ${ }^{6,7,23,24}$ A reduction of norepinephrine release from cardiac adrenergic terminals has been shown after ischemic reperfusion in older animals. ${ }^{7}$ It is also reported that exogenous administration of norepinephrine is able to mimic IP in the senescent heart. The reduction in norepinephrine release after transient ischemic stimulus might thus be responsible for the age-related loss of IP. ${ }^{9}$ Exercise adaptation has been shown to increase the expression of the sarcolemmal $\mathrm{Ca}^{++}$pump protein in the rat heart. It has been found that there is a reduction in the sarcolemmal $\mathrm{Ca}^{++}$pump activity and abnormal sarcoreticular $\mathrm{Ca}^{++}$cycling in the aged heart. ${ }^{24}$ The age-related impairment of calcium transport and excitation-contraction coupling might also result in a loss of the protective effect of IP. The myocardial activity of superoxide dismutase and the production of heat-shock protein decline with age, ${ }^{5,7}$ and these agents are known to play an important role in the IP mechanism. ${ }^{2,22}$ Therefore in the aged heart the absence of IP may be due to the absence of a series of triggers, mediators, and effectors that are involved in the IP protective mechanism.

A review of studies of IP in cardiac surgery reveals that the effect of IP might be age related. In the reports that demonstrate the protective IP phenomenon in cardiac surgery, the patients have been relatively young. The report of Illes and Swoyer ${ }^{15}$ is one with a mean patient age of over 60 years (Table 1). However, the protocol used in that study to induce the protective effects was much different from that in the other 3 studies on elderly patients with a mean age of over 60 years. It has been suggested that the IP stimuli could have caused cumulative effects in the aged myocardium, which is more vulnerable to ischemia. ${ }^{7}$ The IP stimuli needed to induce a protective effect in adult and aged patients, respectively, might therefore be different. Further studies are called for to elucidate this hypothesis.

It is noteworthy that the age definition in the age-related IP effect is relative rather than absolute. Evidence of the IP phenomenon in patients at over 60 years of age suggests that the potential for IP could still in fact remain in an aged person. ${ }^{10}$ In the present study the right ventricular function, which is the most vulnerable in patients with 3-vessel disease undergoing $\mathrm{CABG}$, tended to recover better in the aged patients undergoing IP than in control subjects.

Two periods of 2-minute ischemia, followed by 3-minute reperfusion preconditioning, protects the heart from ischemic reperfusion injury in adult patients with 3-vessel coronary artery disease undergoing CABG. The beneficial effects of IP are manifested in better recovery of right ventricular and global hemodynamic function, better preserved cellular viability, and better surgical outcome. The protective effect declines in aged patients undergoing CABG.

\section{References}

1. Murry CE, Jennings RB, Reimer KA. Preconditioning with ischaemia: a delay of lethal cell injury in ischaemic myocardium. Circulation. 1986;74:1124-36.

2. Przyklenk K, Kloner RA. Ischaemic preconditioning: exploring the paradox. Prog Cardiovasc Dis. 1998;40:517-47.

3. Ferdinandy P, Szilvassy Z, Baxter GF. Adaptation to myocardial stress in disease states: is preconditioning a healthy heart phenomenon? Trends Pharmacol Sci. 1998;19:223-9.

4. Abete P, Ferrara N, Cioppa A, Ferrara P, Bianco S, Calabrese C, et al. Preconditioning does not prevent postischemic dysfunction in aging heart. J Am Coll Cardiol. 1996;27:1777-86.

5. Tani M, Suganuma Y, Hasegawa H, Shinmura K, Hayashi Y, Guo X, et al. Changes in ischaemic tolerance and effects of ischaemic preconditioning in middle-aged rat hearts. Circulation. 1997;95:2559-66.

6. Burns PG, Krunkenkamp IB, Calderone CA, Kirvaitis RJ, Gaudette GR, Levitsky S. Is the preconditioning response conserved in senescent myocardium? Ann Thorac Surg. 1996;61:925-9.

7. Abete P, Ferrara N, Cacciatore F, Madrid A, Bianco S, Calabrese C, et al. Angina-induced protection against myocardial infarction in adult and elderly patients: a loss of preconditioning mechanism in the aging heart? J Am Coll Cardiol. 1997;30:947-54.

8. Napoli C, Liguori A, Cacciatore F, Rengo F, Ambrosio G, Abete P. "Warm-up" phenomenon detected by electrocardiographic ambulatory monitoring in adult and older patients. J Am Geriatr Soc. 1999;47:1114-7.

9. Longobardi G, Abete P, Ferrara N, Papa A, Rosiello R, Furgi G, et al. "Warm-up" phenomenon in adult and elderly patients with coronary artery disease: further evidence of the loss of "ischaemic preconditioning" in the aging heart. J Gerontol A Biol Sci Med Sci. 2000;55:M124-9.

10. Kloner RA, Przyklenk K, Shook T, Cannon CP. Protection conferred by preinfarct angina is manifest in the aged heart: evidence from the TIMI 4 trial. J Thromb Thrombolysis. 1998;6:89-92.

11. Tarkka MR, Wu ZK. Ischaemic preconditioning in cardiopulmonary bypass surgery. Scand Cardiovasc J. 2000;34:231-2.

12. Yellon DM, Alkhulaifi AM, Pugsley WB. Preconditioning the human myocardium. Lancet. 1993;342:276-7.

13. Alkhulaifi AM, Yellon DM, Pugsley WB. Preconditioning the human heart during aorto-coronary bypass surgery. Eur J Cardiothorac Surg. 1994;8:270-6.

14. Lu EX, Chen SX, Yuan MD, Hu TH, Zhou HC, Luo WJ, et al. Preconditioning improves myocardial preservation in patients undergoing open heart operation. Ann Thorac Surg. 1997;64:1320-4.

15. Illes RW, Swoyer KD. Prospective, randomised clinical study of ischaemic preconditioning as an adjunct to intermittent cold blood cardioplegia. Ann Thorac Surg. 1998;65:748-53.

16. Li G, Chen S, Lu E, Li Y. Ischaemic preconditioning improves preservation with cold blood cardioplegia in valve replacement patients. Eur J Cardiothorac Surg. 1999;15:653-7.

17. Szemagala P, Orawski W, Krejca M, Gburek T, Bochenek A. 
Evaluation of perioperative myocardial tissue damage in ischemically preconditioned human heart during aortic coronary bypass surgery. $J$ Cardiovasc Surg (Torino). 1998;39:791-5.

18. Jenkins DP, Pugsley WB, Alkhulaifi Am, Kemp M, Hooper J, Yellon $\mathrm{DM}$. Ischaemic preconditioning reduces troponin $\mathrm{T}$ release in patients undergoing coronary artery bypass surgery. Heart. 1997;77: 314-8.

19. Perrault LP, Menasche P, Bel A, de Chaumaray T, Peynet J, Mondry A, et al. Ischaemic preconditioning in cardiac surgery: a word of caution. J Thorac Cardiovasc Surg. 1996;112:1378-86.

20. Kaukoranta PK, Lepojarvi MP, Ylitalo KV, Kiviluoma KT, Pauhkurinen KJ. Normothermic retrograde blood cardioplegia with or without preceding ischaemic preconditioning. Ann Thorac Surg. 1997;63:1268-74.

21. Cremer J, Steinhoff G, Karck M, Ahnsell T, Brandt M, Teebken OE, et al. Ischaemic preconditioning prior to myocardial protection with cold blood cardioplegia in coronary surgery. Eur J Cardiothorac Surg. 1997;12:753-8.

22. Das DK, Engelman RM, Maulik N. Oxygen free radical signaling in ischaemic preconditioning. Ann N Y Acad Sci. 1999;874:49-65.

23. Paterson DH. Effects of ageing on the cardiorespiratory system. Can $J$ Sport Sci. 1992;17:171-7.

24. Moore RL. Cellular adaptations of the heart muscle to exercise training. Ann Med. 1998;30:I46-53.

Access to The Journal of Thoracic and Cardiovascular Surgery Online is reserved for print subscribers!

Full-text access to The Journal of Thoracic and Cardiovascular Surgery Online is available for all print subscribers. To activate your individual online subscription, please visit The Journal of Thoracic and Cardiovascular Surgery Online, point your browser to http://www.mosby.com/jtcvs, follow the prompts to activate your online access, and follow the instructions. To activate your account, you will need your subscriber account number, which you can find on your mailing label (note: the number of digits in your subscriber account number varies from 6 to 10). See the example below in which the subscriber account number has been circled:

\section{Sample mailing label}

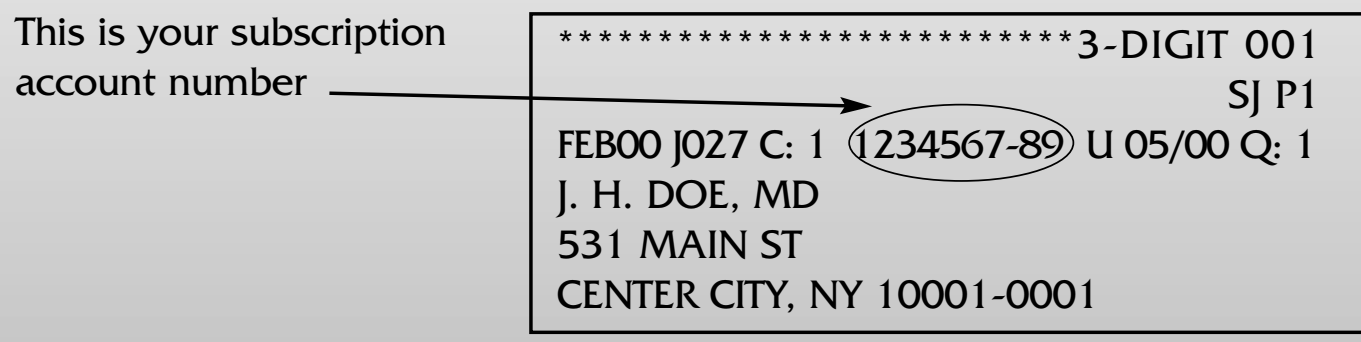

Personal subscriptions to The Journal of Thoracic and Cardiovascular Surgery Online are for individual use only and may not be transferred. Use of The Journal of Thoracic and Cardiovascular Surgery Online is subject to agreement to the terms and conditions as indicated online. 